\title{
Psoriatic arthritis: the role of the nonphysician clinician in the diagnosis and treatment of patients with psoriasis
}

\author{
Michael D. Overcash ${ }^{1}$. Christopher Chillura ${ }^{1}$ - Sarah P. Fender ${ }^{1} \cdot$ Matthew K. Ewald $^{1}$ - Aiken McDowell McNair ${ }^{1}$. \\ Michelle Nye ${ }^{1}$. Clint Blankenship ${ }^{1}$
}

Accepted: 28 January 2021 / Published online: 4 March 2021

(c) The Author(s) 2021

\begin{abstract}
Psoriatic arthritis is a clinically heterogeneous, chronic, and progressive disease that develops in up to $30 \%$ of patients with psoriasis and is characterized by multiple and increasing joint defects caused by persistent immune-mediated inflammation. Several treatment options are available, including multiple biologic agents that inhibit specific cellular mediators of inflammation either directly or indirectly. Early detection and intervention are critical to preventing severe joint damage and pain, necessitating increased awareness and education about this disease for primary providers and nonphysician clinicians. Physician assistants and nurse practitioners, given their role in the primary care setting and within multiple specialty areas such as dermatology and rheumatology, are often the first to see patients who may have psoriatic arthritis. These healthcare providers are increasingly important in the early diagnosis and treatment of this disease. In this review, we provide an overview of psoriasis and psoriatic arthritis and discuss the multiple treatment options that are available for these patients. We also discuss ways to help recognize early joint involvement in the clinic and emphasize the role that nonphysician clinicians play in the care of patients with psoriatic arthritis.
\end{abstract}

\section{Key points}

Psoriatic arthritis, an inflammatory disease, may cause irreversible joint damage in patients with psoriasis.

Physician assistants and nurse practitioners in dermatology and rheumatology, who are well positioned to recognize psoriatic arthritis early, treat patients, and prevent long-term complications, benefit from education on recognizing and treating psoriatic disease to improve outcomes.

Biologics have demonstrated efficacy in several disease domains of psoriatic arthritis, and treatment guidelines generally recommend their use over that of nonbiologic agents.

Michael D. Overcash

michaelovercash@gmail.com

1 College of Health Professions, Medical University of South Carolina, Charleston, SC, USA

\section{Introduction}

Psoriasis is a chronic, inflammatory, dermatologic disease that occurs in $2-3 \%$ of the US population [1,2]. The disease is characterized by erythematous, scaly papules and plaques and causes itching and pain [2]. Psoriasis is highly variable and can range from mild disease with few localized skin patches to more severe cases involving lesions that cover $>10 \%$ of the body [3, 4].

Up to $30 \%$ of patients with psoriasis may develop psoriatic arthritis (PsA), a chronic, progressive, inflammatory disease with the potential to cause irreversible joint damage and disability if left untreated [5-7]. PsA is prevalent in about $0.06-0.25 \%$ of the US population [8] and is primarily diagnosed in patients between the ages of 30 and 50 years $[8,9]$. It occurs equally in men and women and typically develops within 10 years after the onset of psoriasis $[6,10,11]$. Recent population-based studies in the USA observed that prevalence was highest in White patients (3.6\%), followed by African American patients (1.9\%), Hispanic patients (1.6\%), and others (1.4\%) [1]. In an ethnically diverse psoriasis cohort, PsA was found to occur half as frequently in African American as in White patients but was associated with a greater disease 
burden in African American patients [12]. Approximately $80-100 \%$ of patients with PsA will also have psoriasis $[11,13]$.

The persistent immune-mediated inflammation associated with PsA results in destruction of cartilage and bone as well as altered bone remodeling $[14,15]$. Within 2 years of PsA onset, up to $47 \%$ of patients may develop joint erosions in one or more joint [16]. Permanent loss of function is possible in advanced disease [16]. Early diagnosis and therapeutic intervention are critical for delaying structural bone and joint damage as well as improving patients' quality of life (QOL) - a delay of 6 months in diagnosis is linked to worse radiographic and functional outcomes $[17,18]$. International guidelines developed by the Group for Research and Assessment of Psoriasis and Psoriatic Arthritis (GRAPPA) in 2015 and the European League Against Rheumatism (EULAR) in 2019 [19, 20], as well as guidelines developed by the American College of Rheumatology and National Psoriasis Foundation (ACR/NPF) in 2018 [21] provide information regarding treatment of PsA. Healthcare providers (HCPs) in primary care and dermatology settings, including physician assistants (PAs) and nurse practitioners (NPs), are often the first to see patients and therefore play a critical role in the early diagnosis and treatment of those with PsA.

This review provides an overview of PsA and aims to inform the nonphysician clinician on their role in the diagnosis and treatment of the disease and how to apply the information in practice. We also discuss barriers to timely diagnosis and management of PsA and mechanisms that might improve patient care.

\section{Clinical features of psoriatic arthritis (PsA)}

According to the GRAPPA definition, PsA consists of six disease domains: peripheral arthritis, enthesitis (inflammation of the entheses, the area where a tendon or ligament inserts into bone [22, 23]), dactylitis (the swelling of a whole digit [13, 24]), axial involvement, skin manifestations, and nail alterations (Fig. 1) [19]. The disease most frequently affects the joints of the hands and feet, followed by those of the ankles, knees, and shoulders, commonly in an asymmetrical manner. Structural damage includes joint space narrowing and bone erosions [25, 26].

Psoriasis and PsA carry a significant burden and are associated with several comorbidities, including cardiovascular disease, diabetes, obesity, metabolic syndrome, inflammatory bowel disease, risk of malignancies, fatty liver disease, and depression [27, 28]. Moreover, patients with psoriasis and PsA have a reduced QOL, reduced work productivity $[11,29]$, and a shortened life expectancy [30].

\section{Pathophysiology of PsA}

The pathogenesis of PsA is complex and not fully understood but is thought to result from a combination of genetic, immune, and environmental factors. Psoriasis severity, psoriatic nail disease, infection, trauma, stress, and obesity are considered risk factors for the development of PsA; however, it remains unclear whether nail involvement is a predictor of PsA or an early manifestation of PsA [31]. Genetic studies have found PsA to have a strong genetic component [32-34] and have linked several human leukocyte antigen (HLA) genotypes to PsA (e.g., HLA-B*27) [35].

In addition, a series of complex immune signaling pathways involving activated $T$ cells and macrophages contribute to the inflammation underlying PsA [11, 36, 37]. Inflammatory cytokines-such as interleukin (IL)-22, -17, and -23 as well as tumor necrosis factor (TNF)- $\alpha-$ promote inflammation [36]. TNF $\alpha$ and IL-23 are released in response to multiple stimuli, such as trauma or infection, and help activate T-helper type $17\left(\mathrm{Th}_{17}\right)$ cells. $\mathrm{Th}_{17}$ cells produce IL-17A/F, which promotes inflammation, pathologic bone remodeling, and bone and cartilage destruction. $\mathrm{Th}_{17}$ cells also produce other inflammatory cytokines, including TNF, IL-6, and IL-22, further amplifying the inflammatory response [11, 37].

\section{Diagnosis of PsA}

To ensure early detection of PsA, HCPs in primary care and dermatology clinics are encouraged to proactively screen their patients with psoriasis for signs of PsA. Currently, there are no standard or universally accepted clinical diagnostic criteria for PsA [38]. The Classification Criteria for Psoriatic Arthritis (CASPAR criteria), which were developed to classify patients with PsA in clinical studies [39], can serve as useful guidelines for clinicians in primary care or dermatology practice (Table 1) [39, 40]. The CASPAR criteria include items for personal or family history of psoriasis as well as radiographic evidence of new bone formation, highlighting the importance of history of disease and emphasizing the association between PsA and psoriasis.

In addition, various tools have been developed to aid non-rheumatology providers in the diagnosis of PsA. A commonly used screening tool is the Psoriasis Epidemiology Screening Tool (PEST; Fig. 2) [41]. PEST is a validated and user-friendly questionnaire that can help primary care physicians, dermatologists, PAs, and NPs in these settings start a dialogue with their patients with 


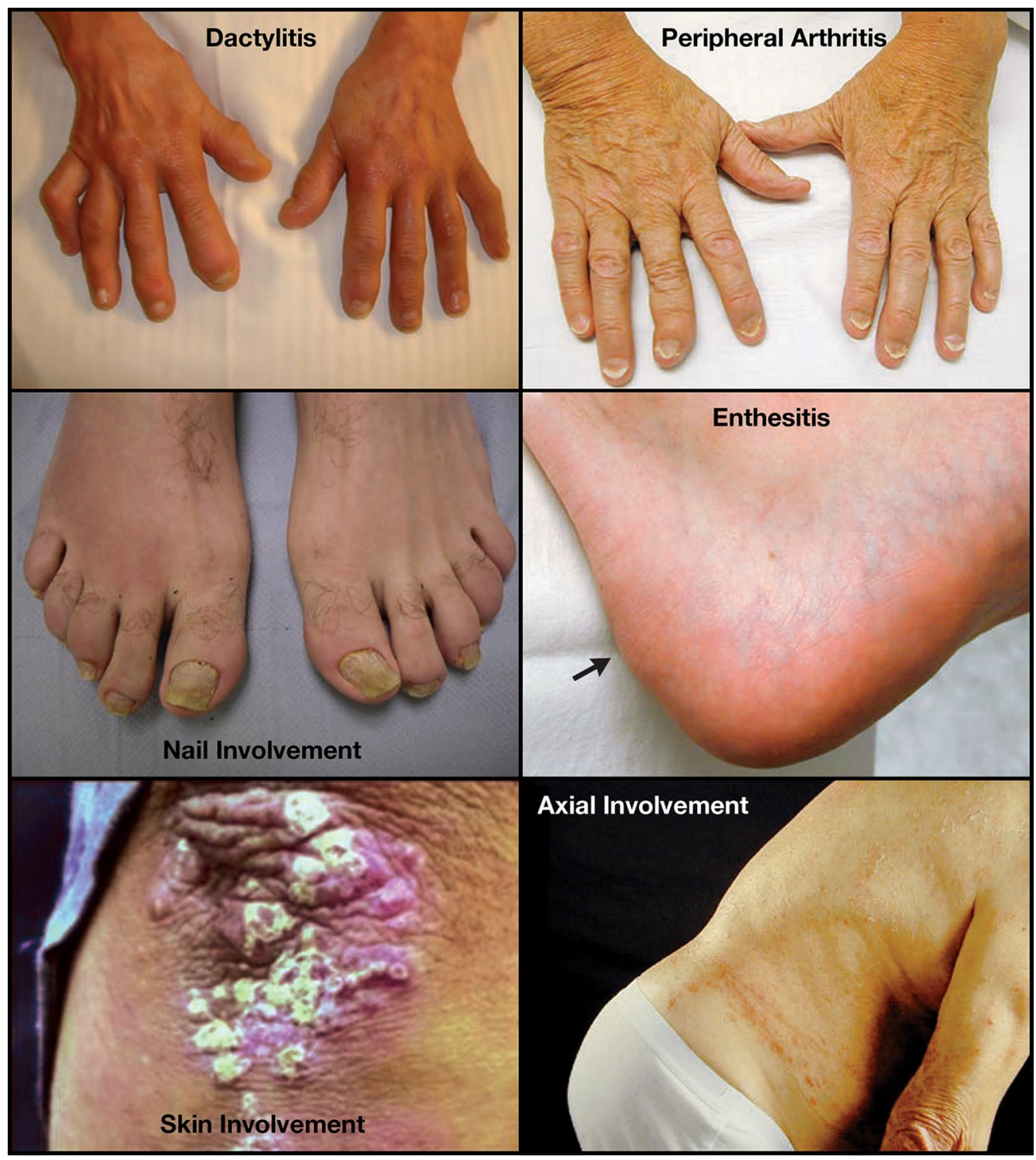

Fig. 1 Photographs showing manifestations of the six domains of psoriatic arthritis: dactylitis (top left) [13], peripheral arthritis (top right) [11], nail involvement (center left) [13], enthesitis (center right) [11], skin involvement (bottom left) [102], and axial involvement (bottom right) [11] Reprinted from Ritchlin et al. [11]. with permis- sion from Massachusetts Medical Society. Copyright (c) 2017 Massachusetts Medical Society. Adapted from Coates and Helliwell [13]. (C) Royal College of Physicians 2017. Reprinted from Kim et al. [102] with permission. () The College of Family Physicians of Canada

\section{Table 1 Classification criteria for psoriatic arthritis (CASPAR criteria) [39]}

\section{CASPAR}

Patient has PsO

Patient does not have $\mathrm{PsO}$, but has a personal history of $\mathrm{PsO}$

Patient does not have $\mathrm{PsO}$ or a personal history of $\mathrm{PsO}$, but does have a family history of PsO

Patient has dactylitis or a history of dactylitis recorded by a rheumatologist

Patient is negative for the presence of rheumatoid factor (by any method except latex)

Patient has radiographic evidence of juxta-articular new bone formation

To meet the CASPAR criteria, a patient must have inflammatory articular disease (joint, spine, or entheseal) with $\geq 3$ points from the table $P s O$ psoriasis 


\begin{tabular}{|l|l|l|}
\hline & NO & YES \\
\hline Have you ever had a swollen joint (or joints)? & & \\
\hline Has a doctor ever told you that you have arthritis? & & \\
\hline Do your finger nails or toe nails have holes or pits? & & \\
\hline Have you had pain in your heel? & & \\
\hline $\begin{array}{l}\text { Have you had a finger or toe that was completely swollen and painful for no } \\
\text { apparent reason? }\end{array}$ & & \\
\hline
\end{tabular}

In the drawing below, please tick the joints that have caused you discomfort (i.e., stiff, swollen, or painful joints).

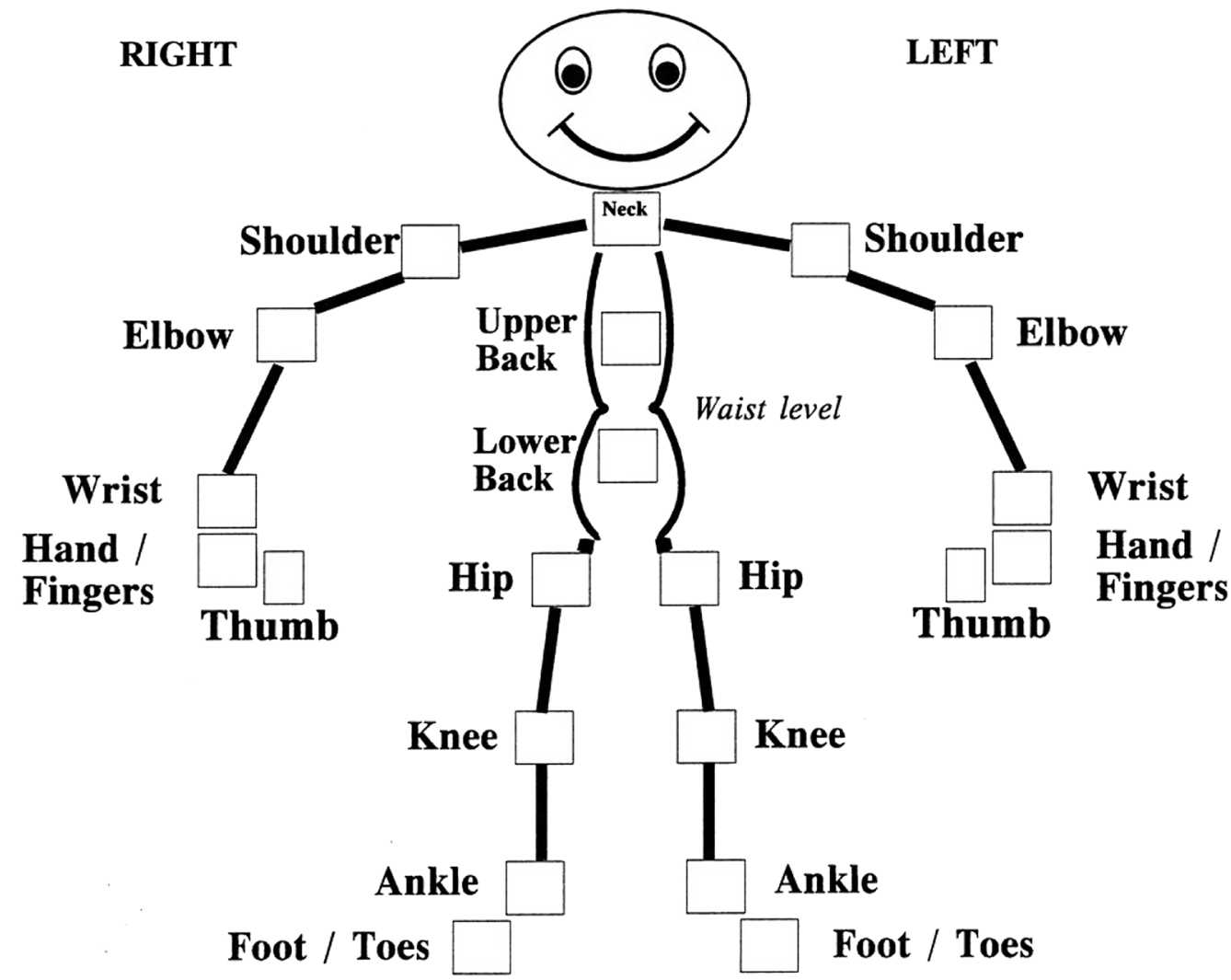

Fig. 2 The Psoriasis Epidemiology Screening Tool (PEST) questions, which can be discussed with patients with psoriasis during a consultation. The diagram allows identification of potentially affected joints

psoriasis [41, 42]. It consists of two parts: a set of five simple questions designed to easily identify patients with signs of PsA and a diagram that helps keep track of painful joints. For example, the PEST asks whether patients have nail pits or holes, pain in their heel, or a finger or toe that was swollen and painful for no apparent reason; a positive response to three of the five questions indicates the
[41]. Reproduced from Ibrahim et al. [41]. (C) Clinical and Experimental Rheumatology 2009

presence of PsA (Fig. 2). In such cases, HCPs screening for PsA (e.g., PAs/NPs in primary or dermatology settings) should refer patients to a rheumatologist [43].

To ensure an accurate diagnosis, HCPs in the rheumatology setting will need to differentiate the symptoms of PsA from those of other arthritides and can use clues provided by each of the six characteristic domains of PsA 
Table 2 Differentiating psoriatic arthritis from other forms of arthritis [11, 38, 103]

\begin{tabular}{llll}
\hline Variable & Psoriatic arthritis & Rheumatoid arthritis & Osteoarthritis \\
\hline Joint distribution & Asymmetrical & Symmetrical & Asymmetrical \\
DIP joint involvement & Common & Rare & Common \\
\hline Number of affected joints & Oligoarticular & Polyarticular & Monoarticular or oligoarticular \\
Areas involved & All joints of a digit & Same joint across digits & Same joints across digits \\
Axial involvement & Common & Uncommon & Common (noninflammatory) \\
\hline Sacroiliitis & Common & Never & Uncommon \\
Ankylosis & Common & Uncommon & Uncommon \\
Nail involvement & Common & Uncommon & Uncommon \\
Dactylitis & Common & Uncommon & Uncommon \\
Enthesitis & Common & Uncommon & Uncommon \\
New bone formation & Common & Never & Common \\
\hline Stiffness after inactivity & Common & Common & Less common \\
Serology & Usually RF negative & Usually RF positive & Usually RF negative
\end{tabular}

$D I P$ distal interphalangeal, $R F$ rheumatoid factor

(Table 2). The peripheral arthritis associated with PsA usually occurs with asymmetrical distribution and involves the distal interphalangeal joints $[25,26]$. Dactylitis is typically an early clinical sign of PsA and is more commonly observed in toes than in fingers [11, 24, 44]. Enthesitis, another early sign of PsA, is more common in the lower extremities; it is generally observed in the plantar fascia, Achilles tendons, and ligamentous attachments to the spine, pelvis, and ribs [9, 45, 46]. Axial involvement may present as asymmetrical sacroiliitis or spondylitis, and patients usually complain of lower back pain that worsens during inactivity [9]. Skin and nail disease is common in patients with PsA; skin manifestations may be hidden in areas such as the scalp, intergluteal and perianal regions, or flexural areas [13]. Common nail dystrophies include oil-drop (or "salmon patch") dyschromia, pitting, white discoloration, nail plate crumbling, and nail ridging-all of which disrupt nail plate attachment-and, eventually, onycholysis. Patients with nail psoriasis have an almost threefold higher risk of developing PsA than patients with psoriasis who lack signs of nail dystrophy, highlighting the need for early detection of nail disease [47-49].

Other diagnostic tools include laboratory tests and imaging. Although no specific laboratory test is available for PsA, it is often characterized by negative results for rheumatoid factor and anti-citrullinated peptides, with possible laboratory abnormalities, including hyperuricemia, elevated C-reactive protein, and prolonged erythrocyte sedimentation rate $[50,51]$. Radiographs allow visualization of PsA-associated features (e.g., new bone formation), and magnetic resonance imaging provides visualization of soft tissue, facilitating the detection of enthesitis and spondylitis [52-55]. However, imaging is not commonly performed in primary care or dermatology settings. Overall, the diagnosis of PsA involves HCPs from multiple specialties, highlighting the importance of collaboration in patient care.

\section{Treatment of PsA}

Treatment of PsA is based on international guidelines developed by GRAPPA in 2015 and EULAR in 2019 [19, 20] and the ACR/NPF guidelines developed in 2018 [21]. The goal of PsA treatment is to achieve remission or minimal/low disease activity $[56,57]$.

Nonsteroidal anti-inflammatory drugs are commonly used as first-line treatment for pain, and adjunctive therapy with intra-articular glucocorticoid steroids may be considered [20]. Patients may then be treated with nonbiologic, conventional synthetic disease-modifying antirheumatic drugs (csDMARDs), biologic DMARDs (bDMARDs or biologics), or targeted synthetic DMARDs (tsDMARDs) [20]. csDMARDs (e.g., methotrexate, sulfasalazine) are commonly used to treat peripheral arthritis and skin disease; however, they often fail to improve enthesitis and axial disease [20, 58-60]. bDMARDs target various cytokines involved in the pathogenesis of PsA and have been shown to improve symptoms and inhibit the progression of structural damage [20, 61]. bDMARDs are typically used in patients in whom csDMARDs have failed, whereas tsDMARDs that inhibit phosphodiesterase-4 or Janus kinases are considered in patients who have experienced an inadequate response to, or are intolerant of, bDMARDs [20]. This section focuses on the use of bDMARDs and tsDMARDs in patients with PsA (Table 3), with several assessment tools used in the clinical trials described in Table 4.

TNF $\alpha$ inhibitors (TNFi) are often used as first-line biologic treatment (Table 3) [20, 21]; however, other biologics, 
Table 3 Biologic and targeted synthetic disease-modifying antirheumatic drugs available for use in patients with psoriatic arthritis

\begin{tabular}{|c|c|c|c|}
\hline $\begin{array}{l}\text { Drug } \\
\text { (admin- } \\
\text { istration } \\
\text { route) }\end{array}$ & $\begin{array}{l}\text { FDA } \\
\text { approval } \\
\text { year for } \\
\text { PsA }\end{array}$ & Clinical trial in pts with active PsA & Clinical efficacy \\
\hline
\end{tabular}

\section{TNF inhibitor}

$\begin{array}{rll}\begin{array}{l}\text { ETA }^{\mathrm{a}} \\ (\mathrm{SC})\end{array} & 2002 & \text { Phase III RCT in 205 pts [104] } \\ \text { ADA }^{\mathrm{b}} & 2005 & \text { Phase III RCT (ADEPT) in } 315 \text { pts [105] } \\ \text { (SC) } & & \end{array}$

$\begin{array}{ll}\text { INF }^{\mathrm{c}} & 2005 \\ (\mathrm{IV}) & \text { Phase III RCT (IMPACT-2) in } 200 \text { pts [106] }\end{array}$

GOL $2009 \quad$ Phase III RCT (GO-REVEAL) in 405 pts [107] (SC)

$2013 \quad$ Phase III RCT (RAPID-PsA) of 409 pts [108]

(SC)

GOL 2017

(IV)

IL-17A inhibitors

SEC 2016

(SC)

IXE (SC) 2017

\section{IL-12/23 inhibitors}

UST 2013

(SC)

013

\section{T-cell modulator}

ABA 2017

(IV/

$\mathrm{SC)}$
Phase III RCT (PSUMMIT-1) of 615 adults [77]

Phase III RCT (PSUMMIT-2) of 312 adults [78]

Phase III RCT (SPIRIT-P1) of 417 biologic-naïve pts [68]

Phase III RCT (SPIRIT-P2) of 363 pts with inadequate response to TNF inhibitors [69]

Phase III H2H RCT (SPIRIT-H2H) of 566 pts [76]

Phase II RCT (PsA-I) of 170 pts with PsO target lesion $\geq 2 \mathrm{~cm}$, previously on DMARDs [110]

Phase III RCT (PsA-II) of 424 pts [111]
ACR20 response: significantly higher with ETA vs. PL at wk 12 (59 vs. $15 \% ; p<0.0001$ ); results sustained at wk 24 and 48

ACR20 response: significantly higher with ADA vs. PL at wk 12 (58 vs. $14 \% ; p<0.001)$ and at wk 24 (57 vs. $15 \% ; p<0.001)$

PASI75 response: significantly higher with ADA vs. PL at wk 24 ( 59 vs. $1 \% ; p<0.001$ )

ACR20 response: significantly higher with INF vs. PL at wk 14 (58 vs. $11 \% ; p<0.001)$

PsA response criteria: significantly higher with INF vs. PL (77 vs. $27 \% ; p<0.001)$

ACR20 response: significantly higher with any dose of GOL (48\%), GOL $50 \mathrm{mg}(51 \%)$, and GOL $100 \mathrm{mg}$ (45\%) vs. PL at wk 14 ( $p<0.001$ for all comparisons)

ACR20 response: significantly higher with CERP $200 \mathrm{mg}$ q2 $\mathrm{w}$ and CERP $400 \mathrm{mg} \mathrm{q} 4 \mathrm{w}$ vs. PL at wk 12 (58.0 and 51.9 vs. $24.3 \% ; p$ $<0.001$ for all comparisons)

ACR20 response: significantly higher with GOL vs. PL at wk 14 (75.1 vs. $21.8 \% ; p<0.001$ )

ACR20 response: significantly higher with SEC $150 \mathrm{mg}$ and 75 mg vs. PL at wk 24 (50.0 and 50.5 vs. $17.3 \% ; p<0.001$ for both comparisons)

ACR20 response: significantly higher with SEC $300 \mathrm{mg}(54 \%)$, SEC $150 \mathrm{mg}(51 \%)$, and SEC $75 \mathrm{mg}(29 \%)$ vs. PL (15\%) at wk 24 ( $p<0.05$ for all comparisons)

ACR20 response: not statistically superior with SEC vs. ADA at wk 52 (67.4 vs. $61.5 \% ; p=0.072$ )

PASI90 response: significantly higher with SEC vs. ADA at wk 52 (65.4 vs. $43.2 \% ; p<0.0001$ )

ACR20 response: significantly higher with IXE q4w vs. PL at wk 24 (57.9 vs. $30.2 \% ; p \leq 0.001$ )

ACR20 response: significantly higher with IXE vs. PL at wk 24 (53 vs. $20 \% ; p<0.0001)$

ACR50 + PASI100 response: significantly higher with IXE vs. ADA at wk 24 ( 36 vs. $28 \% ; p=0.036$ )

ACR50 response: IXE noninferior vs. ADA at wk 24 (50.5 vs. $46.6 \% ; p=0.338)$

PASI100 response: significantly higher with IXE vs. ADA at wk 24 (60.1 vs. $46.6 \% ; p=0.001)$

ACR20 response: significantly higher with UST $45 \mathrm{mg}$ and UST $90 \mathrm{mg}$ vs. PL at wk 24 (42.4 and 49.5 vs. $22.8 \% ; p<0.0001$ for both comparisons)

ACR20 response: significantly higher with UST vs. PL at wk 24 (43.8 vs. $20.2 \% ; p<0.001$ )

ACR response: vs. PL (19\%), significantly higher with ABA 10 $\mathrm{mg} / \mathrm{kg}(48 \% ; p=0.006)$ and ABA $30 / 10 \mathrm{mg} / \mathrm{kg}$ at day $169(42 \%$; $p=0.022)$, but not ABA $3 \mathrm{mg} / \mathrm{kg}(33 \% ; p=0.121)$

ACR20 response: significantly higher with ABA vs. PL at wk 24 (39.4 vs. $22.3 \% ; p<0.001$ ) 
Table 3 (continued)

\begin{tabular}{|c|c|c|c|}
\hline $\begin{array}{l}\text { Drug } \\
\text { (admin- } \\
\text { istration } \\
\text { route) }\end{array}$ & $\begin{array}{l}\text { FDA } \\
\text { approval } \\
\text { year for } \\
\text { PsA }\end{array}$ & Clinical trial in pts with active PsA & Clinical efficacy \\
\hline \multicolumn{4}{|c|}{ tsDMARDs } \\
\hline \multirow[t]{3}{*}{$\begin{array}{l}\text { APR } \\
\text { (oral) }\end{array}$} & \multirow[t]{3}{*}{2014} & $\begin{array}{l}\text { Phase III RCT (PALACE 1) of } 504 \text { pts who } \\
\text { received prior csDMARD and/or biologic } \\
\text { therapy [84] }\end{array}$ & $\begin{array}{l}\text { ACR20 response: significantly higher with APR } 20 \mathrm{mg} \text { BID and } \\
\text { APR } 30 \mathrm{mg} \text { BID vs. PL at wk } 16 \text { ( } 31 \text { and } 40 \text { vs. } 19 \% ; p<0.001 \\
\text { for both comparisons) }\end{array}$ \\
\hline & & $\begin{array}{l}\text { Phase III RCT (PALACE 2) of } 484 \text { pts who } \\
\text { received prior csDMARD and/or biologic } \\
\text { therapy [85] }\end{array}$ & $\begin{array}{l}\text { ACR20 response: vs. PL }(18.9 \%) \text {, significantly higher with APR } \\
20 \mathrm{mg} \text { BID }(37.4 \% ; p=0.0002) \text { and APR } 30 \mathrm{mg} \text { BID }(32.1 \% ; p \\
=0.0060) \text { at wk } 16\end{array}$ \\
\hline & & $\begin{array}{l}\text { Phase III RCT (PALACE 3) of } 505 \text { pts who } \\
\text { received prior csDMARD and/or biologic } \\
\text { therapy [86] }\end{array}$ & $\begin{array}{l}\text { ACR20 response: vs. PL }(18 \%) \text {, significantly higher with APR } \\
20 \mathrm{mg} \text { BID }(28 \% ; p=0.0295) \text { and APR } 30 \mathrm{mg} \text { BID }(41 \% ; p< \\
0.0001) \text { at wk } 16\end{array}$ \\
\hline \multirow[t]{4}{*}{$\begin{array}{l}\text { TOF } \\
\text { (oral) }\end{array}$} & \multirow[t]{4}{*}{2017} & \multirow[t]{2}{*}{$\begin{array}{l}\text { Phase III RCT (OPAL Broaden) of } 422 \text { pts with } \\
\text { inadequate response to previous csDMARDs [87] }\end{array}$} & $\begin{array}{l}\text { ACR20 response: significantly higher with TOF } 5 \text { and } 10 \mathrm{mg} \text { vs. } \\
\text { PL at } 3 \text { mo ( } 50 \text { and } 61 \text { vs. } 33 \% ; p<0.05 \text { for both comparisons) }\end{array}$ \\
\hline & & & $\begin{array}{l}\text { Mean changes in HAQ-DI score }{ }^{\mathrm{d}} \text { : significantly greater improve- } \\
\text { ment with TOF } 5 \text { and } 10 \mathrm{mg} \text { vs. PL at } 3 \mathrm{mo}(-0.35 \text { and }-0.40 \\
\text { vs. }-0.18 ; p<0.01 \text { for both comparisons })\end{array}$ \\
\hline & & \multirow[t]{2}{*}{$\begin{array}{l}\text { Phase III RCT (OPAL Beyond) of } 395 \text { pts with } \\
\text { inadequate response to TNF inhibitors [88] }\end{array}$} & $\begin{array}{l}\text { ACR20 response: significantly higher with TOF } 5 \text { and } 10 \mathrm{mg} \text { vs. } \\
\text { PL ( } 50 \text { and } 47 \text { vs. } 24 \% ; p<0.001 \text { for both comparisons) }\end{array}$ \\
\hline & & & $\begin{array}{l}\text { Mean changes in HAQ-DI score }{ }^{\mathrm{d}} \text { : significantly greater improve- } \\
\text { ment with TOF } 5 \text { and } 10 \mathrm{mg} \text { vs. PL at } 3 \mathrm{mo}(-0.39 \text { and }-0.35 \\
\text { vs. }-0.14 ; p<0.001 \text { for both comparisons })\end{array}$ \\
\hline
\end{tabular}

$A B A$ abatacept, $A C R$ American College of Rheumatology, ACR20 $\geq 20 \%$ improvement in ACR criteria, ACR50 $\geq 50 \%$ improvement in ACR criteria, $A D A$ adalimumab, $A P R$ apremilast, BID twice daily, CERP certolizumab pegol, $c s D M A R D$ conventional synthetic disease-modifying antirheumatic drugs, ETA etanercept, GOL golimumab, $H 2 H$ head-to-head trial, $H A Q-D I$ Health Assessment Questionnaire Disability Index, $I L$ interleukin, $I N F$ infliximab, $I V$ intravenous, $I X E$ ixekizumab, mo month(s), $P A S I 75 / 90 / 100 \geq 75 \%, 90 \%$, and $100 \%$ improvement in Psoriasis Area and Severity Index score from baseline, $P L$ placebo, $P s A$ psoriatic arthritis, $P s O$ psoriasis, $p t s$ patients, $q x w$ every $\times$ weeks, $R C T$ randomized controlled trial, $S C$ subcutaneous, $S E C$ secukinumab, TNF tumor necrosis factor, TOF tofacitinib, tsDMARD targeted synthetic diseasemodifying antirheumatic drug, UST ustekinumab, wk week(s)

${ }^{a}$ Biosimilar to ETA includes etanercept-szzs (approved 2016)

${ }^{\mathrm{b}}$ Biosimilars to ADA include adalimumab-adbm (approved 2017), adalimumab-atto (2016), and adalimumab-adaz (2018)

${ }^{c}$ Biosimilars to INF include infliximab-abda (approved 2017), infliximab-dyyb (2016), and infliximab-qbtx (2017)

${ }^{\mathrm{d}}$ Reductions in HAQ-DI score indicate improvements in disability

such as inhibitors of IL-17, IL-12/23, or IL-23, may be more appropriate first-line biologic treatment in certain situations (e.g., severe psoriasis) [21]. Patients who do not respond to one TNFi can be switched to another TNFi, although other biologics are recommended in case of primary TNFi efficacy failure or intolerance of TNFi [21, 62]. In these cases, IL-17 inhibitors are usually preferred over IL-12/23 inhibitors [21].

IL-17 inhibitors, which include secukinumab and ixekizumab, have also demonstrated efficacy in several disease domains of PsA and were recently recommended as firstline biologics for patients with PsA and skin involvement by the 2019 EULAR guidelines (Table 3) [20, 63-69]. Importantly, secukinumab and ixekizumab have shown efficacy in patients with PsA who had an inadequate response to TNFi therapy [63-67, 69]. Long-term analyses have shown that secukinumab sustained improvements in the symptoms of PsA out to 5 years and inhibition of radiographic progression through 2 years [70, 71], and ixekizumab sustained improvements in the signs and symptoms of PsA through 3 years of treatment [72]. Although IL-17 inhibitors have been shown to be safe in patients with PsA, they should be used with caution in patients with inflammatory bowel disease because they may exacerbate Crohn disease and ulcerative colitis [73, 74]. Moreover, results from two head-to-head trials in biologic-naive patients with PsA suggest IL-17 inhibitors may provide a greater benefit than TNFi in patients who are experiencing both skin and musculoskeletal manifestations (Table 3) [75, 76].

Ustekinumab, an IL-12/-23 inhibitor, is another biologic treatment that has been approved for PsA (Table 3) [77, 78]. However, it is not yet known whether ustekinumab provides benefits similar to those of IL-17 inhibitors in patients with PsA with skin manifestations given that no formal head-tohead comparison between ustekinumab and TNFi has been conducted. 
In July 2020, guselkumab became the first IL-23 inhibitor to receive approval from the US FDA for PsA. Two phase III clinical trials, DISCOVER 1 and 2, found significant improvements in ACR20 at 24 weeks in adult patients, including patients previously treated with TNFi $[79,80]$. In addition to these agents, other biologics, including additional inhibitors of IL-23 (tildrakizumab [81], risankizumab [82]) and IL-17 (bimekizumab [83]), are actively being investigated for the treatment of PsA. Results from these studies may inform future therapeutic strategies.

tsDMARDs have also emerged as treatments for PsA. These include apremilast, an oral phosphodiesterase 4 inhibitor [84-86], and tofacitinib, an oral Janus kinase inhibitor [87, 88] (Table 3). Despite apremilast showing efficacy, in an adjusted, indirect, network meta-analysis comparison study, biologics (secukinumab, infliximab, golimumab) demonstrated superior efficacy versus apremilast in treating multiple domains of PsA [89]. Tofacitinib has been approved only for patients with an inadequate response to, or who were intolerant of, methotrexate or other nonbiologic DMARDs. Despite apremilast and tofacitinib having shown efficacy in patients with PsA who had an inadequate response to TNFi therapy [84-86, 88], treatment guidelines recommend using biologics over these agents in patients with an inadequate response to TNFi [21].

\section{Nonpharmacologic approaches}

Guidelines also exist for treating psoriasis with nonpharmacologic approaches. These include topical therapiessuch as emollients, vitamin D analogues, and tar-that can be valuable and inexpensive adjuncts to newer therapies. Ultraviolet irradiation has also been a time-honored modality for the treatment of psoriasis and has long been recognized as beneficial in controlling psoriatic skin lesions [90]. For patients with active PsA, nonpharmacologic interventions are often recommended regardless of pharmacologic treatment status. According to the 2018 ACR/NPF guidelines, these include low-impact exercises (e.g., tai chi, yoga, swimming), physical therapy, occupational therapy, massage therapy, and acupuncture. In addition, smoking cessation is recommended strongly because of effectiveness demonstrated in both randomized trials and the general population. In patients with PsA who are overweight or obese, weight loss is recommended for its potential to increase pharmacologic response [21].

\section{Barriers to timely diagnosis and management of PsA}

Several barriers contribute to the underdiagnosis and suboptimal care of patients with PsA. Clinicians treating patients with psoriasis are not always aware of the importance of routinely screening their patients for PsA. Similarly, patient education on the signs, symptoms, and risks of PsA is often inadequate. Diagnosis is often delayed because of the heterogeneity of PsA and lack of a defined set of diagnostic criteria [38].

Delays in diagnosis may also result from the long wait times experienced by patients referred to a rheumatologist [91]. The number of rheumatologists in the USA is low, and a decline in the rheumatology workforce is projected through 2030 [92-94]. Furthermore, rheumatology practices are unevenly distributed, with metropolitan areas having a higher density of rheumatologists than rural areas [92, 95]. These findings suggest that, in addition to experiencing long wait times to see a specialist, patients may have to travel long distances, further contributing to delays in diagnosis.

Another barrier is that patients with PsA may not always receive optimal treatment. For instance, more-efficacious agents may not be used because of their higher cost [96-98]. In some cases, patients may continue treatment with less costly and less effective therapies or discontinue new treatment soon after treatment initiation [99]. In other cases, patients may not be able or willing to make multiple physician visits or obtain laboratory tests. Additionally, patients may refuse treatment because of a fear of adverse events, which may stem from concerns over starting a new drug, or from information seen in TV advertisements or other media. This is likely based on the perception that the risks of treatment-associated adverse events are greater than the risks of disease progression.

\section{Improving patient care in PsA}

PAs and NPs play important roles in the diagnosis and treatment of psoriasis and PsA and can help improve the care of patients with PsA. Primary care and dermatology PAs and NPs are often the first to see patients with psoriasis and are therefore ideally positioned to screen them for PsA and refer them to a rheumatologist as needed.

Once patients are referred to a rheumatologist and a diagnosis of PsA has been confirmed, rheumatology PAs/NPs can effectively educate patients on the disease and available treatments. They can also treat patients with PsA and help prevent complications and disease progression by managing treat-to-target (T2T) strategies in rheumatology practice, as has been done previously for patients with rheumatoid arthritis (RA) [56, 100]. T2T strategies focus on disease that is inactive or in remission as the primary target and were shown to improve patient outcomes versus the standard of care in TICOPA, a randomized study in PsA [101]. These findings suggest that PAs and NPs should be trained in T2T strategies as part of their education. 
Table 4 Key assessments of psoriatic arthritis

\section{ACR20/50/70 response [112]}

Patients must show a $\geq 20 \%, 50 \%$, or $70 \%$ improvement in swollen and tender joint counts, and three of five other measures

Patient global assessment

Physician global assessment

Patient-reported pain

Patient-reported physical function

Acute-phase reactants (CRP or ESR)

MDA [113]

A patient is classified as achieving MDA when meeting five or more of the following seven criteria

Tender joint count $\leq 1$

Swollen joint count $\leq 1$

PASI $\leq 1$ or BSA $\leq 3$

Patient pain VAS $\leq 15$

Patient global disease activity VAS $\leq 20$

Health assessment questionnaire $\leq 0.5$

Tender entheseal points $\leq 1$

HAQ-DI [114]

20 items divided into eight domains: dressing and grooming, arising, eating, walking, hygiene, reach, grip, and common daily activities

Subjects rate the degree of difficulty they have had in the past week on a 4-point scale, ranging from 0 (no difficulty) to 3 (unable to do)

The highest scores in each category are summed (0-24) and divided by the number of categories scored to yield a score from 0 to 3

DLQI [115]

10-item questionnaire to measure how much a patient's skin problem has affected their life over the last week (range 0-30)

$0-1$ : no effect at all on patient's life

2-5: small effect on patient's life

6-10: moderate effect on patient's life

11-20: very large effect on patient's life

21-30: extremely large effect on patient's life

PASI [116]

Measure of overall psoriasis severity and coverage, consisting of two major steps

Calculate the patient's BSA covered with lesions-each region of the body (head, upper limbs, trunk, lower limbs) is given a score representing the proportion involved: 1 (0-9\%), 2 (10-29\%), 3 (30-49\%), 4 (50-69\%), 5 (70-89\%), or 6 (90-100\%)

Assessment of the severity of lesions, which consists of assessing lesions' erythema (redness), induration (thickness), and scaling-each plaque sign is assessed on a 5-point scale: 0 (none), 1 (mild), 2 (moderate), 3 (severe), or 4 (very severe)

All calculations are combined into a single score (PASI score) in the range of 0 (no psoriasis on the body) to 72 (the most severe case of psoriasis)

Scores are summed and weighted by region (head $=0.1$; upper limbs $=0.2$; trunk $=0.3$; lower limbs $=0.4$ )

$A C R$ American College of Rheumatology, BSA body surface area, $C R P$, C-reactive protein, DLQI Dermatology Life Quality Index, ESR erythrocyte sedimentation rate, HAQ-DI Health Assessment Questionnaire Disability Index, MDA minimal disease activity, PASI Psoriasis Area and Severity Index, VAS visual analog score

The ACR Workforce studies have also underscored the important role that nonphysician clinicians have in treating PsA. To help close the gap between supply and demand for rheumatology services, these studies suggested increasing the recruitment of PAs and NPs into rheumatology practices and developed a web-based rheumatology curriculum for PAs and NPs [92-94]. An initiative by the ACR and Association of Rheumatology Professionals is also actively considering formal rheumatology programs for NPs and PAs, which would improve PsA patient care [92].

\section{Conclusions}

Psoriasis is a complex disease that extends beyond skin manifestations. A substantial proportion of patients with psoriasis develop PsA and are at risk of experiencing irreversible and disabling joint damage. Therefore, early diagnosis and intervention with therapies that effectively treat all aspects of psoriatic disease are necessary in these patients. Nonphysician clinicians are well positioned to identify patients with PsA and increasingly play larger roles in the early diagnosis, treatment, and education of these patients. Further utilization 
of nonphysician clinicians is needed to improve the care of patients with psoriatic disease.

Acknowledgements The authors thank Karen Chinchilla, $\mathrm{PhD}$, of ArticulateScience LLC, Hamilton, NJ, USA, and Eric Deutsch, PhD, CMPP, of Health Interactions, Inc, Hamilton, NJ, USA, for providing medical writing support/editorial support, which was funded by Novartis Pharmaceuticals Corporation, East Hanover, NJ, USA, in accordance with Good Publication Practice guidelines (http://www. ismpp.org/gpp3).

\section{Declarations}

Funding Novartis Pharmaceuticals Corporation, East Hanover, NJ, USA, provided funding for medical writing support in accordance with Good Publication Practice guidelines (http://www.ismpp.org/gpp3) and sponsored the open access fees for this article.

Conflict of interest M.D. Overcash has served as a speaker or advisor for BioPlus, Novartis, Celgene, Bayer HealthCare, Pfizer, Sonoma, IQVIA, Amerita, Ranbaxy, Cipher Pharmaceuticals, Blue Sky, and The Dominion Group. C. Chillura, S.P. Fender, M.K. Ewald, A.M. McNair, M. Nye, and C. Blankenship have no conflicts of interest that are directly relevant to the content of this article.

Availability of data and material Not applicable.

Ethics approval Not applicable.

Consent to participate Not applicable.

Consent for publication Not applicable.

Code availability Not applicable.

Author contributions M. D. Overcash developed the first draft of the article with the help of a medical writer funded by Novartis Pharmaceuticals Corporation. All authors provided input, reviewed the manuscript, and approved submission of this draft for publication.

Open Access This article is licensed under a Creative Commons Attribution-NonCommercial 4.0 International License, which permits any non-commercial use, sharing, adaptation, distribution and reproduction in any medium or format, as long as you give appropriate credit to the original author(s) and the source, provide a link to the Creative Commons licence, and indicate if changes were made. The images or other third party material in this article are included in the article's Creative Commons licence, unless indicated otherwise in a credit line to the material. If material is not included in the article's Creative Commons licence and your intended use is not permitted by statutory regulation or exceeds the permitted use, you will need to obtain permission directly from the copyright holder. To view a copy of this licence, visit http://creativecommons.org/licenses/by-nc/4.0/.

\section{References}

1. Rachakonda TD, Schupp CW, Armstrong AW. Psoriasis prevalence among adults in the United States. J Am Acad Dermatol. 2014;70:512-6.

2. Elmets CA, Leonardi CL, Davis DMR, et al. Joint AAD-NPF guidelines of care for the management and treatment of psoriasis with awareness and attention to comorbidities. J Am Acad Dermatol. 2019;80:1073-113.

3. Langley RGB, Krueger GG, Griffiths CEC. Psoriasis: epidemiology, clinical features, and quality of life. Ann Rheum Dis. 2005;64(suppl II):ii18-23.

4. Hawkes JE, Chan TC, Krueger JG. Psoriasis pathogenesis and the development of novel targeted immune therapies. J Allergy Clin Immunol. 2017;140:645-53.

5. Mease PJ, Gladman DD, Papp KA, et al. Prevalence of rheumatologist-diagnosed psoriatic arthritis in patients with psoriasis in European/North American dermatology clinics. J Am Acad Dermatol. 2013;69:729-35.

6. Gladman DD, Antoni C, Mease P, et al. Psoriatic arthritis: epidemiology, clinical features, course, and outcome. Ann Rheum Dis. 2005;64(suppl 2):ii14-7.

7. Wilson FC, Icen M, Crowson CS, et al. Time trends in epidemiology and characteristics of psoriatic arthritis over 3 decades: a population-based study. J Rheumatol. 2009;36:361-7.

8. Ogdie A, Weiss P. The epidemiology of psoriatic arthritis. Rheum Dis Clin N Am. 2015;41:545-68.

9. Gottlieb A, Korman NJ, Gordon KB, et al. Guidelines of care for the management of psoriasis and psoriatic arthritis: Section 2. Psoriatic arthritis: overview and guidelines of care for treatment with an emphasis on the biologics. J Am Acad Dermatol. 2008;58:851-64.

10. Catanoso M, Pipitone N, Salvarani C. Epidemiology of psoriatic arthritis. Reumatismo. 2012;64:66-70.

11. Ritchlin CT, Colbert RA, Gladman DD. Psoriatic arthritis. N Engl J Med. 2017;376:957-70.

12. Kerr GS, Qaiyumi S, Richards J, et al. Psoriasis and psoriatic arthritis in African-American patients-the need to measure disease burden. Clin Rheumatol. 2015;34:1753-9.

13. Coates LC, Helliwell PS. Psoriatic arthritis: state of the art review. Clin Med (Lond). 2017;17:65-70.

14. Sankowski AJ, Lebkowska UM, Cwikla J, et al. Psoriatic arthritis. Pol J Radiol. 2013;78:7-17.

15. McArdle A, Flatley B, Pennington SR, et al. Early biomarkers of joint damage in rheumatoid and psoriatic arthritis. Arthritis Res Ther. 2015;17:141.

16. Kane D, Stafford L, Bresnihan B, et al. A prospective, clinical and radiological study of early psoriatic arthritis: an early synovitis clinic experience. Rheumatology (Oxford). 2003;42:1460-8.

17. Gladman DD, Thavaneswaran A, Chandran V, et al. Do patients with psoriatic arthritis who present early fare better than those presenting later in the disease? Ann Rheum Dis. 2011;70:2152-4.

18. Haroon M, Gallagher P, Fitzgerald O. Diagnostic delay of more than 6 months contributes to poor radiographic and functional outcome in psoriatic arthritis. Ann Rheum Dis. 2015;74:1045-50.

19. Coates LC, Kavanaugh A, Mease PJ, et al. Group for Research and Assessment of Psoriasis and Psoriatic Arthritis 2015 treatment recommendations for psoriatic arthritis. Arthritis Rheumatol. 2016;68:1060-71.

20. Gossec L, Baraliakos X, Kerschbaumer A, et al. EULAR recommendations for the management of psoriatic arthritis with pharmacological therapies: 2019 update. Ann Rheum Dis. 2020;79:700-12.

21. Singh JA, Guyatt G, Ogdie A, et al. Special article: 2018 American College of Rheumatology/National Psoriasis Foundation guideline for the treatment of psoriatic arthritis. Arthritis Rheumatol. 2019;71:5-32.

22. Kaeley GS, Eder L, Aydin SZ, et al. Enthesitis: a hallmark of psoriatic arthritis. Semin Arthritis Rheum. 2018;48:35-53.

23. Apostolakos J, Durant TJ, Dwyer CR, et al. The enthesis: a review of the tendon-to-bone insertion. Muscles Ligaments Tendons J. 2014;4:333-42. 
24. Kaeley GS, Eder L, Aydin SZ, et al. Dactylitis: a hallmark of psoriatic arthritis. Semin Arthritis Rheum. 2018;48:263-73.

25. van der Heijde D, Sharp J, Wassenberg S, et al. Psoriatic arthritis imaging: a review of scoring methods. Ann Rheum Dis. 2005;64(suppl 2):ii61-4.

26. Wassenberg S. Radiographic scoring methods in psoriatic arthritis. Clin Exp Rheumatol. 2015;33(5 suppl 93):S55-9.

27. Ogdie A, Schwartzman S, Husni ME. Recognizing and managing comorbidities in psoriatic arthritis. Curr Opin Rheumatol. 2015;27:118-26.

28. Husni ME. Comorbidities in psoriatic arthritis. Rheum Dis Clin N Am. 2015;41:677-98.

29. Lee S, Mendelsohn A, Sarnes E. The burden of psoriatic arthritis: a literature review from a global health systems perspective. Pharm Ther. 2010;35:680-9.

30. McLaughlin M, Ostor A. Early treatment of psoriatic arthritis improves prognosis. Practitioner. 2014;258:21-4.

31. Ogdie A, Gelfand JM. Clinical risk factors for the development of psoriatic arthritis among patients with psoriasis: a review of available evidence. Curr Rheumatol Rep. 2015;17:64.

32. Chandran V, Schentag CT, Brockbank JE, et al. Familial aggregation of psoriatic arthritis. Ann Rheum Dis. 2009;68:664-7.

33. Karason A, Love TJ, Gudbjornsson B. A strong heritability of psoriatic arthritis over four generations-the Reykjavik Psoriatic Arthritis Study. Rheumatology (Oxford). 2009;48:1424-8.

34. Rahmati S, Tsoi L, O'Rielly D, et al. Complexities in genetics of psoriatic arthritis. Curr Rheumatol Rep. 2020;22:10.

35. Veale DJ, Fearon U. The pathogenesis of psoriatic arthritis. Lancet. 2018;391:2273-84.

36. Boutet MA, Nerviani A, Gallo Afflitto G, et al. Role of the IL-23/IL-17 axis in psoriasis and psoriatic arthritis: the clinical importance of its divergence in skin and joints. Int J Mol Sci. 2018;19:E530.

37. Smith JA, Colbert RA. Review: the interleukin-23/interleukin-17 axis in spondyloarthritis pathogenesis: Th17 and beyond. Arthritis Rheumatol. 2014;66:231-41.

38. McArdle A, Pennington S, FitzGerald O. Clinical features of psoriatic arthritis: a comprehensive review of unmet clinical needs. Clin Rev Allergy. 2018;55:271-94.

39. Taylor W, Gladman D, Helliwell P, et al. Classification criteria for psoriatic arthritis: development of new criteria from a large international study. Arthritis Rheum. 2006;54:2665-73.

40. Mease PJ, Armstrong AW. Managing patients with psoriatic disease: the diagnosis and pharmacologic treatment of psoriatic arthritis in patients with psoriasis. Drugs. 2014;74:423-41.

41. Ibrahim GH, Buch MH, Lawson C, et al. Evaluation of an existing screening tool for psoriatic arthritis in people with psoriasis and the development of a new instrument: the Psoriasis Epidemiology Screening Tool (PEST) questionnaire. Clin Exp Rheumatol. 2009;27:469-74.

42. Mease PJ, Palmer JB, Hur P, et al. Utilization of the validated Psoriasis Epidemiology Screening Tool to identify signs and symptoms of psoriatic arthritis among those with psoriasis: a cross-sectional analysis from the US-based Corrona Psoriasis Registry. J Eur Acad Dermatol Venereol. 2019;33:886-92.

43. Lenman M, Abraham S. Diagnosis and management of psoriatic arthropathy in primary care. J R Coll Gen Pract. 2014;64:424-5.

44. Gladman DD. Clinical features and diagnostic considerations in psoriatic arthritis. Rheum Dis Clin N Am. 2015;41:569-79.

45. Polachek A, Cook R, Chandran V, et al. The association between sonographic enthesitis and radiographic damage in psoriatic arthritis. Arthritis Res Ther. 2017;19:189.

46. Polachek A, Li S, Chandran V, Gladman DD. Clinical enthesitis in a prospective longitudinal psoriatic arthritis cohort: incidence, prevalence, characteristics, and outcome. Arthritis Care Res (Hoboken). 2017;69:1685-91.
47. Sobolewski P, Walecka I, Dopytalska K. Nail involvement in psoriatic arthritis. Reumatologia. 2017;55:131-5.

48. Raposo I, Torres T. Nail psoriasis as a predictor of the development of psoriatic arthritis. Actas Dermosifiliogr. 2015;106:452-7.

49. Rouzaud M, Sevrain M, Villani AP, et al. Is there a psoriasis skin phenotype associated with psoriatic arthritis? Systematic literature review. J Eur Acad Dermatol Venereol. 2014;28(suppl 5):17-26.

50. Punzi L, Podswiadek M, Oliviero F, et al. Laboratory findings in psoriatic arthritis. Reumatismo. 2007;59(suppl 1):52-5.

51. AlJohani R, Polachek A, Ye JY, et al. Characteristic and outcome of psoriatic arthritis patients with hyperuricemia. J Rheumatol. 2018;45:213-7.

52. Poggenborg RP, Sorensen IJ, Pedersen SJ, et al. Magnetic resonance imaging for diagnosing, monitoring and prognostication in psoriatic arthritis. Clin Exp Rheumatol. 2015;33(5 suppl 93):S66-9.

53. Ostergaard M, Eshed I, Althoff CE, et al. Whole-body magnetic resonance imaging in inflammatory arthritis: systematic literature review and first steps toward standardization and an OMERACT scoring system. J Rheumatol. 2017;44:1699-705.

54. Sudol-Szopinska I, Matuszewska G, Kwiatkowska B, et al. Diagnostic imaging of psoriatic arthritis. Part I: etiopathogenesis, classifications and radiographic features. J Ultrason. 2016;16:65-77.

55. Sudol-Szopinska I, Pracon G. Diagnostic imaging of psoriatic arthritis. Part II: magnetic resonance imaging and ultrasonography. J Ultrason. 2016;16:163-74.

56. Tucker LJ, Ye W, Coates LC. Novel concepts in psoriatic arthritis management: can we treat to target? Curr Rheumatol Rep. 2018;20:71.

57. Coates LC, FitzGerald O, Merola JF, et al. Group for Research and Assessment of Psoriasis and Psoriatic Arthritis/Outcome Measures in Rheumatology consensus-based recommendations and research agenda for use of composite measures and treatment targets in psoriatic arthritis. Arthritis Rheumatol. 2018;70:345-55.

58. Nash P, Clegg DO. Psoriatic arthritis therapy: NSAIDs and traditional DMARDs. Ann Rheum Dis. 2005;64(suppl 2):ii74-7.

59. Pincus T, Bergman MJ, Yazici Y. Limitations of clinical trials in chronic diseases: is the efficacy of methotrexate (MTX) underestimated in polyarticular psoriatic arthritis on the basis of limitations of clinical trials more than on limitations of MTX, as was seen in rheumatoid arthritis? Clin Exp Rheumatol. 2015;33(5 suppl 93):S82-93.

60. Lie E, van der Heijde D, Uhlig T, et al. Effectiveness and retention rates of methotrexate in psoriatic arthritis in comparison with methotrexate-treated patients with rheumatoid arthritis. Ann Rheum Dis. 2010;69:671-6.

61. D'Angelo S, Tramontano G, Gilio M, et al. Review of the treatment of psoriatic arthritis with biological agents: choice of drug for initial therapy and switch therapy for non-responders. Open Access Rheumatol. 2017;9:21-8.

62. Merola JF, Lockshin B, Mody EA. Switching biologics in the treatment of psoriatic arthritis. Semin Arthritis Rheum. 2017;47:29-37.

63. Mease PJ, McInnes IB, Kirkham B, et al. Secukinumab inhibition of interleukin-17A in patients with psoriatic arthritis. N Engl J Med. 2015;373:1329-39.

64. McInnes IB, Mease PJ, Kirkham B, et al. Secukinumab, a human anti-interleukin-17A monoclonal antibody, in patients with psoriatic arthritis (FUTURE 2): a randomised, double-blind, placebocontrolled, phase 3 trial. Lancet. 2015;386:1137-46.

65. Nash P, Mease PJ, McInnes IB, et al. Efficacy and safety of secukinumab administration by autoinjector in patients with 
psoriatic arthritis: results from a randomized, placebo-controlled trial (FUTURE 3). Arthritis Res Ther. 2018;20:47.

66. Kivitz AJ, Nash P, Tahir H, et al. Efficacy and safety of subcutaneous secukinumab $150 \mathrm{mg}$ with or without loading regimen in psoriatic arthritis: results from the FUTURE 4 study. Rheumatol Ther. 2019;6:393-407.

67. Mease P, van der Heijde D, Landewé R, et al. Secukinumab improves active psoriatic arthritis symptoms and inhibits radiographic progression: primary results from the randomised, double-blind, phase III FUTURE 5 study. Ann Rheum Dis. 2018;77:890-7.

68. Mease PJ, van der Heijde D, Ritchlin CT, et al. Ixekizumab, an interleukin-17A specific monoclonal antibody, for the treatment of biologic-naive patients with active psoriatic arthritis: results from the 24-week randomised, double-blind, placebo-controlled and active (adalimumab)-controlled period of the phase III trial SPIRIT-P1. Ann Rheum Dis. 2017;76:79-87.

69. Nash P, Kirkham B, Okada M, et al. Ixekizumab for the treatment of patients with active psoriatic arthritis and an inadequate response to tumour necrosis factor inhibitors: results from the 24-week randomised, double-blind, placebo-controlled period of the SPIRIT-P2 phase 3 trial. Lancet. 2017;389:2317-27.

70. Mease PJ, Kavanaugh A, Reimold A, et al. Secukinumab provides sustained improvements in the signs and symptoms of psoriatic arthritis: final 5-year results from the phase 3 FUTURE 1 study. ACR Open Rheumatol. 2020;2:18-25.

71. Mease P, Landewé R, Rahman P, et al. Effect of secukinumab on radiographic progression through 2 years in patients with active psoriatic arthritis: end-of-study results from a phase III study. Arthritis Rheumatol. 2019;71(suppl 10):1554.

72. Orbai AM, Gratacós J, Turkiewicz A, et al. Efficacy and safety of ixekizumab in patients with psoriatic arthritis and inadequate response to TNF inhibitors: 3-year follow-up (SPIRIT-P2). Rheumatol Ther. 2020 (Epub ahead of print).

73. Taltz (ixekizumab) [prescribing information]. Indianapolis, Eli Lilly and Company; 2020.

74. Cosentyx (secukinumab) [prescribing information]. East Hanover: Novartis Pharmaceuticals Corporation; 2020.

75. McInnes IB, Behrens F, Mease PJ, et al. Secukinumab versus adalimumab for treatment of active psoriatic arthritis (EXCEED): a double-blind, parallel-group, randomised, active-controlled, phase 3b trial. Lancet. 2020;395:1496-505.

76. Mease PJ, Smolen JS, Behrens F, et al. A head-to-head comparison of the efficacy and safety of ixekizumab and adalimumab in biological-naïve patients with active psoriatic arthritis: 24-week results of a randomised, open-label, blinded-assessor trial. Ann Rheum Dis. 2020;79:123-31.

77. McInnes IB, Kavanaugh A, Gottlieb AB, et al. Efficacy and safety of ustekinumab in patients with active psoriatic arthritis: 1 year results of the phase 3, multicentre, double-blind, placebo-controlled PSUMMIT 1 trial. Lancet. 2013;382:780-9.

78. Ritchlin C, Rahman P, Kavanaugh A, et al. Efficacy and safety of the anti-IL-12/23 p40 monoclonal antibody, ustekinumab, in patients with active psoriatic arthritis despite conventional nonbiological and biological anti-tumour necrosis factor therapy: 6-month and 1-year results of the phase 3, multicentre, doubleblind, placebo-controlled, randomised PSUMMIT 2 trial. Ann Rheum Dis. 2014;73:990-9.

79. Deodhar A, Helliwell PS, Boehncke WH, et al. Guselkumab in patients with active psoriatic arthritis who were biologic-naive or had previously received $\mathrm{TNF} \alpha$ inhibitor treatment (DISCOVER-1): a double-blind, randomised, placebo-controlled phase 3 trial. Lancet. 2020;395:1115-25.

80. Mease PJ, Rahman P, Gottlieb AB, et al. Guselkumab in biologicnaive patients with active psoriatic arthritis (DISCOVER-2): a double-blind, randomised, placebo-controlled phase 3 trial. Lancet. 2020;395:1126-36.

81. Mease PJ, Chohan S, García Fructuoso FJ, et al. Randomised, double-blind, placebo-controlled, multiple-dose, phase $2 \mathrm{~b}$ study to demonstrate the safety and efficacy of tildrakizumab, a highaffinity anti-interleukin-23p19 monolconal antibody, in patients with active psoriatic arthritis. Ann Rheum Dis. 2019;78:A78.

82. Mease P, Kellner H, Morita A, et al. Efficacy and safety of risankizumab, a selective IL-23p19 inhibitor, in patients with active psoriatic arthritis over 24 weeks: results from a phase 2 trial. Ann Rheum Dis. 2018;77:A200.

83. Ritchlin CT, Kavanaugh A, Merola JF, et al. Bimekizumab in patients with active psoriatic arthritis: results from a 48-week, randomised, double-blind, placebo-controlled, dose-ranging phase 2b trial. Lancet. 2020;395:427-40.

84. Kavanaugh A, Mease PJ, Gomez-Reino JJ, et al. Treatment of psoriatic arthritis in a phase 3 randomised, placebo-controlled trial with apremilast, an oral phosphodiesterase 4 inhibitor. Ann Rheum Dis. 2014;73:1020-6.

85. Cutolo M, Myerson GE, Fleischmann RM, et al. A Phase III, randomized, controlled trial of apremilast in patients with psoriatic arthritis: results of the PALACE 2 trial. J Rheumatol. 2016;43:1724-34.

86. Edwards CJ, Blanco FJ, Crowley J, et al. Apremilast, an oral phosphodiesterase 4 inhibitor, in patients with psoriatic arthritis and current skin involvement: a phase III, randomised, controlled trial (PALACE 3). Ann Rheum Dis. 2016;75:1065-73.

87. Mease P, Hall S, Fitzgerald O, et al. Tofacitinib or adalimumab versus placebo for psoriatic arthritis. N Engl J Med. 2017;377:1537-50.

88. Gladman D, Rigby W, Azevedo VF, et al. Tofacitinib for psoriatic arthritis in patients with an inadequate response to TNF inhibitors. N Engl J Med. 2017;377:1525-36.

89. McInnes IB, Nash P, Ritchlin C, et al. Secukinumab for psoriatic arthritis: comparative effectiveness versus licensed biologics/apremilast: a network meta-analysis. J Comp Eff Res. 2018;7:1107-23.

90. Menter A, Strober BE, Kaplan DH, et al. Joint AAD-NPF guidelines of care for the management and treatment of psoriasis with biologics. J Am Acad Dermatol. 2019;80:1029-72.

91. Widdifield J, Bernatsky S, Thorne JC, et al. Wait times to rheumatology care for patients with rheumatic diseases: a data linkage study of primary care electronic medical records and administrative data. CMAJ Open. 2016;4:E205-12.

92. Battafarano DF, Ditmyer M, Bolster MB, et al. 2015 American College of Rheumatology Workforce Study: supply and demand projections of adult rheumatology workforce, 2015-2030. Arthritis Care Res (Hoboken). 2018;70:617-26.

93. Deal CL, Hooker R, Harrington T, et al. The United States rheumatology workforce: supply and demand, 2005-2025. Arthritis Rheum. 2007;56:722-9.

94. Bolster MB, Bass AR, Hausmann JS, et al. 2015 American College of Rheumatology Workforce Study: the role of graduate medical education in adult rheumatology. Arthritis Care Res (Hoboken). 2018;70:817-25.

95. American College of Rheumatology Committee on Rheumatology Training and Workforce Issues, FitzGerald JD, Battistone $\mathrm{M}$, et al. Regional distribution of adult rheumatologists. Arthritis Rheum. 2013;65:3017-25.

96. Gu T, Shah N, Deshpande G, et al. Comparing biologic cost per treated patient across indications among adult US managed care patients: a retrospective cohort study. Drugs Real World Outcomes. 2016;3:369-81.

97. Cheng J, Feldman SR. The cost of biologics for psoriasis is increasing. Drugs Context. 2014;3:212266. 
98. D’Angiolella LS, Cortesi PA, Lafranconi A, et al. Cost and cost effectiveness of treatments for psoriatic arthritis: a systematic literature review. Pharmacoeconomics. 2018;36:567-89.

99. Walsh JA, Adejoro O, Chastek B, et al. Treatment patterns among patients with psoriatic arthritis treated with a biologic in the United States: descriptive analyses from an administrative claims database. J Manag Care Spec Pharm. 2018;24:623-31.

100. Solomon DH, Bitton A, Fraenkel L, et al. Roles of nurse practitioners and physician assistants in rheumatology practices in the US. Arthritis Care Res (Hoboken). 2014;66:1108-13.

101. Coates LC, Moverley AR, McParland L, et al. Effect of tight control of inflammation in early psoriatic arthritis (TICOPA): a UK multicentre, open-label, randomised controlled trial. Lancet. 2015;386:2489-98

102. Kim WB, Jerome D, Yeung J. Diagnosis and management of psoriasis. Can Fam Physician. 2017;63:278-85.

103. Zhang A, Kurtzman DJB, Perez-Chada LM, et al. Psoriatic arthritis and the dermatologist: an approach to screening and clinical evaluation. Clin Dermatol. 2018;36:551-60.

104. Mease PJ, Kivitz AJ, Burch FX, et al. Etanercept treatment of psoriatic arthritis: safety, efficacy, and effect on disease progression. Arthritis Rheum. 2004;50:2264-72.

105. Mease PJ, Gladman DD, Ritchlin CT, et al. Adalimumab for the treatment of patients with moderately to severely active psoriatic arthritis: results of a double-blind, randomized, placebocontrolled trial. Arthritis Rheum. 2005;52:3279-89.

106. Antoni C, Krueger GG, de Vlam K, et al. Infliximab improves signs and symptoms of psoriatic arthritis: results of the IMPACT 2 trial. Ann Rheum Dis. 2005;64:1150-7.

107. Kavanaugh A, McInnes I, Mease P, et al. Golimumab, a new human tumor necrosis factor alpha antibody, administered every four weeks as a subcutaneous injection in psoriatic arthritis: twenty-four-week efficacy and safety results of a randomized, placebo-controlled study. Arthritis Rheum. 2009;60:976-86.
108. Mease PJ, Fleischmann R, Deodhar AA, et al. Effect of certolizumab pegol on signs and symptoms in patients with psoriatic arthritis: 24-week results of a phase 3 double-blind randomised placebo-controlled study (RAPID-PsA). Ann Rheum Dis. 2014;73:48-55.

109. Kavanaugh A, Husni ME, Harrison DD, et al. Safety and efficacy of intravenous golimumab in patients with active psoriatic arthritis: results through week twenty-four of the GO-VIBRANT study. Arthritis Rheumatol. 2017;69:2151-61.

110. Mease P, Genovese MC, Gladstein G, et al. Abatacept in the treatment of patients with psoriatic arthritis: results of a sixmonth, multicenter, randomized, double-blind, placebo-controlled, phase II trial. Arthritis Rheum. 2011;63:939-48.

111. Mease PJ, Gottlieb AB, van der Heijde D, et al. Efficacy and safety of abatacept, a T-cell modulator, in a randomised, doubleblind, placebo-controlled, phase III study in psoriatic arthritis. Ann Rheum Dis. 2017;76:1550-8.

112. Felson DT, Anderson JJ, Boers M, et al. American College of Rheumatology. Preliminary definition of improvement in rheumatoid arthritis. Arthritis Rheum. 1995;38:727-35.

113. Coates LC, Fransen J, Helliwell PS. Defining minimal disease activity in psoriatic arthritis: a proposed objective target for treatment. Ann Rheum Dis. 2010;69:48-53.

114. Fries JF, Spitz P, Kraines RG, et al. Measurement of patient outcome in arthritis. Arthritis Rheum. 1980;23:137-45.

115. Finlay AY, Khan GK. Dermatology Life Quality Index (DLQI)-a simple practical measure for routine clinical use. Clin Exp Dermatol. 1994;19:210-6.

116. Fredriksson T, Pettersson U. Severe psoriasis-oral therapy with a new retinoid. Dermatologica. 1978;157:238-44. 